\title{
Impact of online social capital on academic performance: exploring the mediating role of online knowledge sharing
}

\author{
Ghasem Salimi $^{1} \cdot$ Elham Heidari $^{1}$ D $\cdot$ Mahboobe Mehrvarz ${ }^{1} \cdot$ Ali Akbar Safavi ${ }^{1}$
}

Received: 18 May 2021 / Accepted: 22 December 2021 / Published online: 20 January 2022

(C) The Author(s), under exclusive licence to Springer Science+Business Media, LLC, part of Springer Nature 2022

\begin{abstract}
Given the importance of digital communication during the COVID-19 pandemic, the need for advancing academic goals through online social capital is more tangibly felt. This study examined the hypothesis that online social capital can improve the students' academic performance, as one of the main academic goals, through the mediation of knowledge sharing in the online environment. Participants in the study were 376 graduate engineering students from five universities in Iran. The findings indicated that the bridging of online social capital had a positive and significant effect on the cognitive and social integrative benefits of online knowledge sharing. Besides, the social integrative benefits and personal integrative benefits of online knowledge sharing influenced academic performance. Finally, the social integrative benefits and personal integrative benefits had a mediating role in the relationship between the bridging of online social capital and academic performance. Implications of the findings are discussed for the students' academic performance and suggestions are provided for future research.
\end{abstract}

Keywords Online Social Capital $\cdot$ Knowledge Sharing · Academic Performance · Structural Equation Modeling · Higher Education

Elham Heidari

eheidari@shirazu.ac.ir

Ghasem Salimi

salimi@shirazu.ac.ir

Mahboobe Mehrvarz

mehrvarzmahboobe66@yahoo.com

Ali Akbar Safavi

safavi@shirazu.ac.ir

1 Shiraz University, Shiraz, Iran 


\section{Introduction}

Like other aspects of life, educational institutions and student learning have been considerably influenced by the crisis of COVID-19 (Almanthari et al., 2020; Heidari et al., 2021; Toquero, 2020). Accordingly, many scholars (e.g., Ahmed et al., 2020) have examined the students' academic performance during the COVID19 pandemic, as one of the most important indicators of success in universities (Mthimunye \& Daniels, 2020), to identify the programs and activities that have the greatest impact on the students' academic performance (Mehrvarz et al., 2021; Aslam et al., 2014). In this regard, researchers have highlighted the significance of social capital in improving the students' academic performance during the pandemic (Ahmed et al., 2020).

Social capital is one of the most important processes of dealing with natural crises, including the COVID-19 crisis (Borgonovi \& Andrieu, 2020; Pitas \& Ehmer, 2020; Wu, 2021). Communities with high social capital respond more efficiently to society (Bartscher et al., 2020; Pitas \& Ehmer, 2020) and have more professional identities (Heidi et al., 2020) than communities with low social capital. Moreover, as Ahmed et al.'s (2020) study suggested, students with high social capital and communication skills interact more with their instructors and peers, and these benefits will enhance their academic performance (Ahmed et al., 2020). Although social capital communication skills often start in face-to-face communication, online techniques and web platforms support the development of relationships through shared structures (Al-Ansari et al., 2019). Online-offline tools allow individuals to interact with others within and outside social networks to develop and maintain social capital, which is correspondingly reinforced and supported by its members' desires (Perez et al., 2020).

Given the positive impact of social capital on improving students' academic performance, the main question that arises concerns how students' academic performance increases through their social capital. Based on the literature, it appears that the amount of information sharing among students can affect their performance. Knowledge sharing, a mechanism used to share, integrate, interpret, and apply information, can also help to do better activities and gain more benefits (Almeida \& Soares, 2014). According to Yu et al. (2010a), knowledge sharing also refers to the sharing of community-related information, ideas, and suggestions among individuals. Therefore, the quality of relationships and trust between individuals is influenced by their willingness to share knowledge (Chen et al., 2014). One of the factors affecting academic performance is the benefits of online knowledge sharing, which can also be influenced by online trust-based social capital. Consequently, it seems that social capital can affect the students' academic performance both directly and indirectly through the benefits of online knowledge sharing.

Although various studies have been carried out in this regard, Crompton and Burke (2018), in their systematic review, indicated that despite the importance of using digital tools and cyberspace capabilities for improving the academic performance of graduate students, this group has not been adequately studied in 
the literature. Our review suggested that the few studies conducted on this group examined the relationship between online social capital, online knowledge sharing, and academic performance in pairs. Hence, the present study aims to investigate the relationships among the three elements (i.e., online social capital, online knowledge sharing, and academic performance) together, focusing on graduate students at various public universities and higher education institutions in Iran.

\section{Literature review}

With the current speed of digitalization, the pace of technological change has also accelerated (Hubbard, 2019). The need to understand the digital world and learn how to work with it is felt more and more today (Nouri et al., 2020), and universities are no exception in this regard. In a situation where learning is mainly technologydriven, especially with the emergence of COVID-19, improving the students' academic performance has become one of the main concerns of the universities at various academic levels worldwide (Bevins et al., 2020). Academic performance, as one of the requirements for students' achievement (Mthimunye \& Daniels, 2020), refers to the students' ability to perform classroom tasks, do problem-solving activities, handle academic affairs (Yuet al., 2010b), accomplish homework assignments, and get satisfactory grade point averages (Hung, 2005).

Academic performance can be influenced and improved by various factors, such as the use of new technologies and social media (Edmunds et al., 2021; Bouton et al., 2021; Ahmed et al., 2020); COVID-19 pandemic, and remote education (Iglesias-Pradas et al., 2021). Iglesias-Pradas et al. (2021) compare students' academic performance during the COVID-19 pandemic and previous years. Their results showed distance and emergency education during the COVID-19 pandemic have increased students' academic performance. Academic performance can also be influenced by social capital (Ahmed et al., 2020; Behtoui \& Neergaard, 2016), which is associated with the significant interaction of users in different communities (Hall \& Widén-Wulff, 2008). Online social capital and academic performance of university students are two important and interrelated issues that can define the effectiveness of the students' social and academic activities in universities (Ahmed et al., 2020). Online social capital refers to the access of individuals to the ties in a network, which increases their trust and group norms (Paige et al., 2017). One of the famous theories of online social capital is Putnam's (2000) theory, which is the basis of the theoretical framework of this study. Putnam's (2000) proposed online social capital was characterized by "bridging" and "bonding." Bridging social capital is inclusive, creates little emotional support, weak ties, and allows people with different backgrounds to interact in social media (Putnam, 2000; Lin, 2017). In contrast, bonding social capital is exclusive media (Putnam, 2000) and is defined as individuals' close emotional relationships and companionship based on a shared identity (Fong et al., 2020).

A review of the related literature readily shows that online social capital is positively and significantly associated with academic performance (Oranye et al., 2017; Ahmed et al., 2020). For example, Behtoui and Neergaard (2016), in a study 
that investigated the relationship between social capital and students' educational achievement, concluded that all three dimensions of social capital (structural, communication, and cognitive) in a family environment have a positive impact on the students' educational achievement. Daly et al. (2020) in a study conducted on five elementary schools in Southern California, also indicated that teachers' both human and social capitals have a significant and positive effect on student achievement. During the COVID-19, Iqbal et al. (2021) examined the "effect of emotional intelligence and academic social networking sites on academic performance pandemic". Their results showed that academic social networking sites, along with emotional intelligence, play a positive and important role in fostering students' academic performance during the COVID-19 epidemic. In another study, Islam et al. (2018) found that social capital, derived from the use of smartphones, can have a positive and significant impact on the students' performance. As discussed above, some studies indirectly highlighted the importance of social capital in improving learners' performances in different educational contexts and at various levels. However, to the best of our knowledge, no research has directly examined the relationship between social capital, especially with an emphasis on bridging and bonding dimensions, and graduate students' academic performance. In their systematic review, Crompton and Burke (2018) also pointed to the gap that despite the importance of using digital tools and cyberspace capabilities for the academic performance of graduate students, this group has been less investigated in the literature. However, based on the studies reviewed above, the following hypotheses can be proposed:

- Bridging of online social capital has a positive and significant effect on the students' academic performance (H1-1).

- Bonding of online social capital has a positive and significant effect on the students' academic performance (H1-2).

Besides the relationship between online social capital and academic performance of students, research has also focused on the impact of knowledge sharing on the students' academic performance, with knowledge sharing being defined as a process by which individuals share their knowledge, expertise, insight, or understanding in a tacit or explicit way (Ford \& Staples, 2010). In the process of online knowledge sharing, people could learn and apply knowledge (Ma \& Yuen, 2011). This learning is usually acquired through sharing interests, goals, needs, or practices (Chiu et al., 2006). One of the theoretical frameworks of knowledge sharing is Tonteri et al.'s (2017) which considers three main benefits for online knowledge sharing, namely, "cognitive benefits" (CB), "social integrative benefits" (SIB), and "personal integrating benefits" (PIB). CB refers to a person's expectations of developing his knowledge as well as problem-solving ability. SIB refers to a person's expectations of networking and connecting with members of the virtual community, and PIB refers to a person's expectations to improve his status as an expert and to influence others (Tonteri et al., 2011). This study used Tonteri et al.'s (2017) theory for investigating the advantages of online knowledge sharing in improving the students' academic performance. 
Various studies have investigated the relationship between the tendency to share knowledge and academic performance (Chiu \& Hsu, 2006; Shah \& Mahmood, 2016; Moghavvemi et al., 2018). In fact, During the Covid-19 pandemic, technology played an important role in improving teachers' teaching performance and became an important medium in sharing knowledge and education (Suparsa et al., 2021). Asterhan and Bouton (2017), for instance, found that sharing course materials and maintaining positive attitudes toward online knowledge sharing improve students' academic performance. Moreover, Eid and Al-Jabri (2016), in a study on 308 graduate and undergraduate students at a university in Saudi Arabia, suggested that knowledge sharing strongly affects learning performance. Moghavvemi et al.'s (2018) study on 170 Malaysian undergraduate students revealed trust and perceived reciprocal benefit as two strong predictors of knowledge sharing amongst students that affect their academic performance and recognition. Some studies examined the indirect role of knowledge sharing and students' academic performance. For example, in a study, Rasto et al.(2021) examined the relationship between knowledge sharing and students' academic performance with the mediating role of competence. They concluded that knowledge sharing has a positive effect on students' academic performance with the mediating role of competence. In another study conducted by Shah and Mahmood (2016) on 360 final semester students revealed that explicit knowledge sharing indirectly and tacit knowledge directly affect students' performance.

Although the relationship between knowledge sharing and the students' academic performance was investigated in various studies, no study has examined the influence that various knowledge sharing benefits (i.e., CB, SIB, and PIB) can have on the students' academic performance. Moreover, as Sharabati (2018) indicates, factors affecting the students' knowledge sharing vary across people with different cultural backgrounds (like the Iranians). Besides, the majority of the studies had their focus on undergraduate, rather than graduate, students. However, based on the information available, the following assumptions were made about how the various advantages of knowledge sharing can affect the academic performance of students, particularly within the Iranian context, which constitutes the focus of the current investigation:

- CB has a positive and significant effect on students' academic performance (H21).

- SIB has a positive and significant effect on students' academic performance (H2-2).

- PIB has a positive and significant effect on students' academic performance (H23).

Nevertheless, although knowledge sharing can improve the students' academic performance, it is quite significant to consider the factors that increase the studens' tendency to share knowledge, especially in online environments (Liao, 2017). One such factor is the online social capital that improves students' knowledge sharing in online communities (García-Sánchez et al., 2019). In this process, the level of dependence and a sense of belonging to the online learning platform is important. 
In general, the higher expectations people have of the online social community, the more likely they are to share knowledge (Li, 2015).

The relationship between online social capital and online knowledge sharing can be readily seen in the literature (Sabatini \& Sarracino, 2014; Chiu et al., 2006; Zhang et al., 2017). Lefebvre et al. (2016), in a piece of research with 150 members of 16 European learning networks, examined the social capital and knowledge sharing performance of learning networks and stated that social interaction and cognitive social capital are positively and significantly related to knowledge sharing in learning networks. A study by García-Sánchez et al. (2019) with 87 academic research teams at a Spanish university also showed that social capital has a positive and significant effect on the research teams' knowledge sharing. Zhang et al. (2017) examined the social capital motivations and knowledge sharing intention of 363 members from health Q\&A communities in China and indicated that social capital has a positive effect on the intention of professionals and normal users to share knowledge. Al-Ansari et al. (2019), in a paper entitled "Moderating role of m-Learning activities in the relationship between students' social capital and knowledge sharing", with 312 undergraduate university students in Bahrain, concluded that there is a positive relationship between social capital and knowledge sharing, which means that social capital is a valuable mechanism through which universities can share knowledge. For this reason, it is recommended that universities increase confidence, networks, and standards among lecturers to facilitate knowledge sharing.

As mentioned above, there are many studies considering the relationship between social capital and knowledge sharing. However, few studies have examined the relationship between the various dimensions of the online social capital dimension (i.e., Bridging and Bonding) and the various benefits of online knowledge sharing (i.e., CB, SIB, and PIB). Moreover, few studies investigated the effect of social capital and knowledge sharing on graduated students in an online environment. Accordingly, we can make the following hypotheses:

- Bridging of online social capital has a positive and significant effect on the CB of students' knowledge sharing (H3-1).

- Bridging of online social capital has a significant and positive effect on SIB in students' knowledge sharing (H3-2).

- Bridging of online social capital has a positive and significant effect on PIB of students' knowledge sharing (H3-3).

- Bonding of online social capital has a positive and significant effect on the CB of students' knowledge sharing (H3-4).

- Bonding of online social capital has a positive and significant effect on the SIB of students (H3-5).

- Bonding of online social capital has a positive and significant effect on PIB of students (H3-6).

Furthermore, the previous research has examined the impact of each of the three variables (i.e., online social capital, academic performance, and online knowledge sharing) on academic performance individually. No studies have investigated the interaction of these three variables and their impact on the students' academic 
performance simultaneously. Given the purpose of the study to verify how these variables interact to affect the students' academic performance, the last hypothesis we made was as follows:

- The various dimensions of online knowledge sharing play a role in mediating the relationship between the dimensions of online social capital and students' academic performance $(\mathrm{H} 4)$.

Based on these hypotheses, the proposed research model is presented in fig. 1.

\section{Methods}

\subsection{Study design and sample}

This study benefited from a descriptive method of correlation type using structural equation modeling, which examines the direct and indirect causal structural relations among variables using a correlation scheme. The questionnaires, described more fully below, were distributed among the Iranian engineering graduate students of two public universities and three private higher education institutions in 2020. In order to consider the diversity of universities in Iran in the field of engineering, representative samples were selected from large public comprehensive universities, medium public universities of technology, private comprehensive higher education institutions, and private higher education institutions of technology. This study used a stratified random sampling, with the diversity of universities as marker variables. That random samples were selected from each stratum. From the statistical population ( $\mathrm{N}=4277), 376$ students were selected as the study sample using the Morgan table. All students participated voluntarily and received no incentive for their participation. The descriptive features of the sample, as presented in Table 1, were

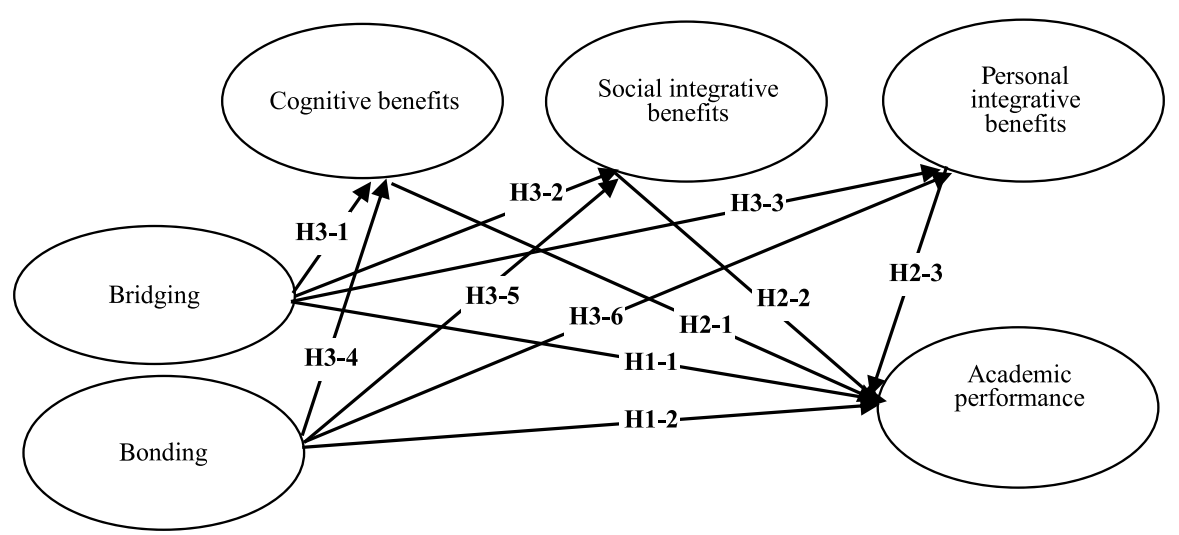

Fig. 1 Proposed model 


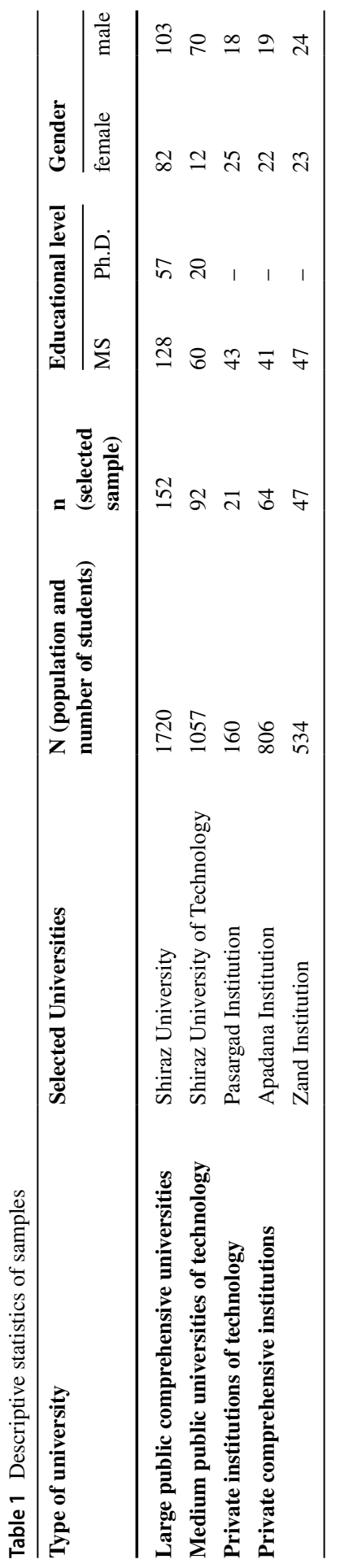


found quite similar to those of the population data at the public university and private institutions.

\subsection{Instruments}

\subsubsection{Online social capital}

In order to measure online social capital, Paige et al.'s (2017) 5-point Likert scale $(1=$ strongly disagree; $5=$ strongly agree) questionnaire was used. This instrument includes two main dimensions, namely "online bridging social capital" and "online bonding social capital." The former includes seven items and was designed by making changes to Ellison et al.'s (2007) questionnaire. The latter includes five items that were designed by applying changes to William's (2006) questionnaire items. It should be noted that this instrument has been previously tested on college students, with its reliability on Cronbach's $\alpha$ level being 0.92 for the whole instrument (Heidari et al., 2020), and 0.85 for each of the bridging and bonding sections (Paige et al., 2017). However, the rigor of this instrument for graduate students was estimated in the current investigation. For its validity, confirmatory factor analysis was performed. The results of the confirmatory factor analysis are presented in the results section. The reliability of the bonding and bridging dimensions was correspondingly found 0.90 and 0.87 on Cronbach's $\alpha$ level.

\subsubsection{Benefits of online knowledge sharing}

In order to verify which advantages of online knowledge sharing are of main concern to the participants, the questionnaire designed by Liao (2017) was used. This instrument includes three dimensions. The first dimension is $\mathrm{CB}$ and includes two items. The second dimension is SIB with two items and the third dimension is PIB with 3 items. The reliability of this tool has been investigated in different studies. For example, in Liao's (2017) study, the Cronbach's alpha coefficient for the CB, SIB, and PIB dimensions were correspondingly estimated to be $0.91,0.86$, and 0.90 . In this research, the rigor of the instrument was investigated for graduate students. To investigate its validity, confirmatory factor analysis was performed (Brown, 2015), the results of which are presented in the results section. On the other hand, the reliability of the questionnaire was verified by estimating the coefficients of alpha for each of the $\mathrm{CB}$, SIB, and PIB dimensions, which were found to be $0.80,0.84$, and 0.91 , respectively.

\subsubsection{Academic performance}

To examine the academic performance of the participants, the questionnaire designed by $\mathrm{Yu}$ et al. (2010b) was used. It is a perceived academic performance questionnaire that measures students' perception of their academic performance by a self-report questionnaire. This instrument includes four items. Although previous studies had confirmed the reliability of this instrument for different groups of participants (e.g., Yu et al., 2010b; Zhou, 2017; Nkhoma et al., 2015), in the current investigation, its rigor 
was considered specifically for graduate students. Content analysis and confirmatory factor analysis were performed to ascertain the validity of this instrument; the results are presented in the results section. On the other hand, Cronbach's alpha, with coefficient of 0.80 corroborated the reliability of the instrument for the stated participants.

\section{Analyses}

The SPSS data analysis software (version 22) was used to obtain the descriptive statistics and perform the analyses concerning the validity of the questionnaires used in the study. On the other hand, structural equation modeling (SEM) was performed, and model fitness was estimated in AMOS (version 21.0). Following Brown (2015), the indices that were considered to examine model fitness included: chi-square $\left(\chi^{2}\right)$, the chi-square/degrees of freedom, the incremental fit index (IFI), the comparative fit index (CFI), and the root-mean-square error of approximation (RMSEA). The appropriate level for the first two indices (i.e., chi-square/degrees of freedom) was considered below 3; for IFI and CFI, the acceptable level was greater than 0.90, and for RMSEA, it was less than 0.08 (Brown, 2015).

\section{Results}

Table 2 demonstrates the means, standard deviations, skewness, kurtosis and correlations (r) for all the research variables. The means ranged from 3.97 to 2.37 , and the standard deviations ranged from 0.79 to 1.09 . Skewness and kurtosis statistics were used to check the normality of the variables. As it can be noticed, all the variables met Hair Jr et al., 's (2016) kurtosis and skewness threshold of -1 and 1, hence the normaility of the variables and the appropriateness of the model for SEM analysis. On the other hand, the results of correlation analysis, as presented in Table 2, indicate that both dimensions of online social capital are significantly correlated with all the benefits of knowledge sharing and academic performance. However, the bonding dimension of online social capital shows no significant correlation with the CB of knowledge sharing and academic performance. The relationship between all aspects of knowledge sharing and academic performance is also significant.

Table 2 Means, standard deviations, correlations and reliabilities

\begin{tabular}{lllllllllll}
\hline Variables & M & SD & Skew & Kurt & $\mathbf{1}$ & $\mathbf{2}$ & $\mathbf{3}$ & $\mathbf{4}$ & $\mathbf{5}$ & $\mathbf{6}$ \\
\hline 1. Bridging & 2.99 & 0.88 & -0.06 & -0.16 & & & & & \\
2. Bonding & 2.37 & 1.09 & 0.47 & -0.66 & $0.58^{* *}$ & & & & \\
3. CB & 3.97 & 0.76 & -0.74 & 0.88 & $0.11^{*}$ & 0.02 & & & \\
4. SIB & 3.88 & 1.04 & -0.47 & 0.19 & $0.24^{* *}$ & $0.10^{*}$ & $0.41^{* *}$ & & & \\
5. PIB & 3.64 & 0.79 & -0.46 & 0.35 & $0.28^{* *}$ & $0.18^{* *}$ & $0.56^{* *}$ & $0.48^{* *}$ & & \\
$\begin{array}{l}\text { 6. Academic } \\
\text { perfor- }\end{array}$ & 3.68 & 0.79 & -0.70 & 0.81 & $0.10^{*}$ & 0.08 & $0.15^{* *}$ & $0.16^{* *}$ & $0.21^{* *}$ & \\
mance & & & & & & & & & & \\
\hline
\end{tabular}




\subsection{Measurement Model}

Confirmatory factor analysis was used to evaluate the measurement model. Construct reliability and convergent validity were used to evaluate the measurement model. Construct reliability was assessed using composite reliability (CR). Both CR values, which ranged from 0.62 to 0.87 , and Cronbach's alpha coefficients, which were higher than 0.80, were above the threshold value of 0.60 (Fornell \& Larcker, 1981). The convergent validity of the measurement model was assessed using average variance extracted (AVE) and confirmatory factor analysis. The AVE for the dimensions of each construct, except SIB, was above the acceptable level of 0.5 (Hair et al., 1998). According to Fornell and Larcker (1981), the convergent validity of a construct can still be considered adequate even if AVE is less than 0.5 but CR is higher than 0.6. The results showed that the factor loadings for each variable of online bridging social capital were between 0.64 and 0.81 , and the factor loadings of each variable of online bonding social capital were between 0.66 and 0.86 . On the other hand, the factor loadings for each variable of the knowledge sharing benefits were as follows: $\mathrm{CB}$ ranged from 0.70 to 0.77 , SIB ranged from 0.62 to 0.72 , and PIB ranged from 0.68 to 0.73 . The factor loadings of each item of the academic performance also ranged between 0.63 and 0.79 (See Table 3).

\subsection{Structural Model}

Structural equation modeling was used to investigate the research hypotheses. Analyses showed that the structural model of the study was well-fitting (Table 4).

As Fig. 2 illustrates, the findings suggest that online bridging social capital had no significant relationship with the students' academic performance $(\beta=0.01$, $p=0.94$ ). Therefore, the hypothesis of $1-1$ (bridging has a positive and significant effect on the students' academic performance) was not approved. Similarly, online bonding social capital had no significant relationship with academic performance ( $\beta=0.02, p=0.85$ ), thus rejecting the hypothesis of 1-2 (bonding has a positive and significant effect on the students' academic performance). Moreover, CB had no significant relationship with academic performance, and the hypothesis of 2-1 (CB has a positive and significant effect on students' academic performance) was thereby disapproved. On the other hand, SIB had a positive and significant relationship with academic performance $(\beta=0.20, p=0.04)$, thereby confirming the hypothesis of $2-2$ (SIB has a positive and significant effect on students' academic performance). In addition, PIB had a positive and significant relationship with academic performance ( $\beta=0.27, p=0.01$ ), thus corroborating the hypothesis of $2-3$ (PIB has a positive and significant effect on students' academic performance). The results further revealed positive significant relationships between online bridging social capital and $\mathrm{CB}$ $(\beta=0.25, p=0.01)$, SIB $(\beta=0.50, p=0.0001)$, and PIB $(\beta=0.36, p=0.0001)$, which lend credence to research hypotheses $3-1$ (bridging has a positive and significant effect on the students' CB), 3-2 (bridging has a significant and positive effect on students' SIB), and 3-3 (bridging has a positive and significant effect on students' PIB). On the contrary, no significant relationship was found between online bonding social capital and any dimensions of knowledge sharing, namely CB, SIB, and PIB; 


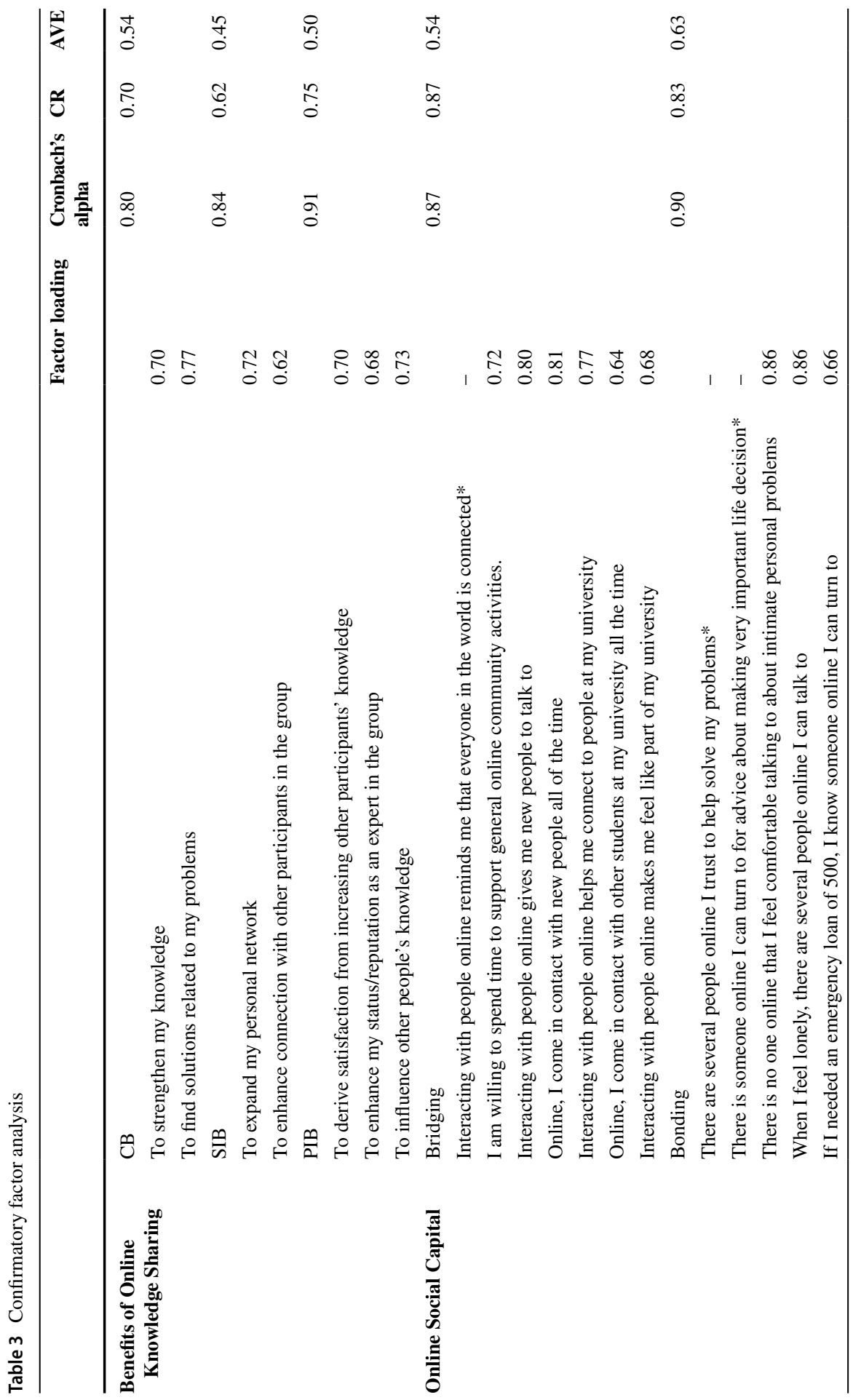




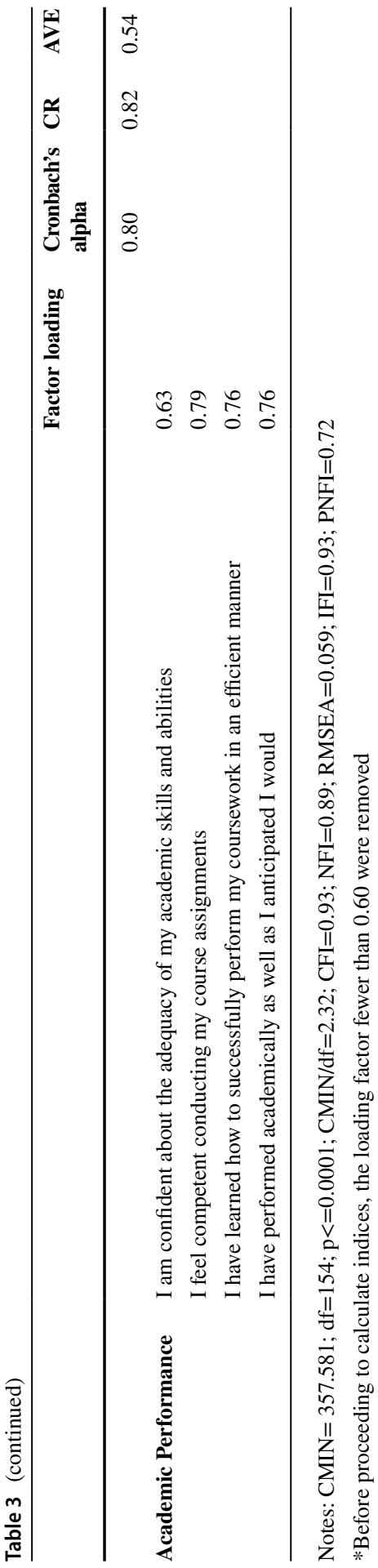


Table 4 Fit indices of the structural model

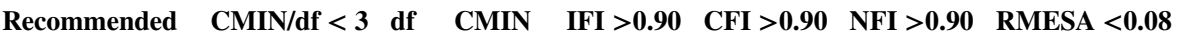
cut-off points

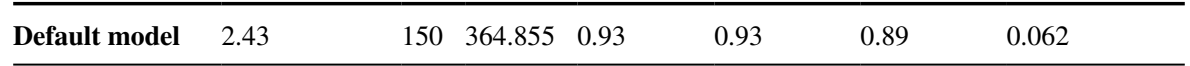

hence, hypotheses 3-4 (bonding has a positive and significant effect on the students' CB), 3-5 (bonding has a positive and significant effect on the SIB of students), and 3-6 (bonding has a positive and significant effect on PIB of students) of the study were not approved.

Regarding the mediating role of online knowledge sharing in the relationship between online social capital and academic performance, it should be noted that only the link between bridging of social capital, SIB, and academic performance, as well as the link between bridging of online social capital, PIB and academic performance, were significant. Therefore, the mediating role of SIB and PIB in the relationship between online bridging social capital and academic performance were considered. The results repudiated the direct effect of bridging of social capital on academic performance $(\beta=0.01)$, while its indirect effect mediated by PIB and SIB was confirmed, correspondingly with $\beta=0.09$ and $\beta=0.10$. The finding corroborates Hypothesis 4 of the study, which concerned the mediating role of SIB and PIB (Tables 5 and 6).

\section{Discussion}

The purpose of the present study was to investigate the relationship between online social capital and the academic performance of engineering students, considering the mediating role of the benefits of online knowledge sharing.

Based on the results, hypotheses 1-1 (bridging of online social capital has a positive and significant effect on the students' academic performance) and 1-2 (bonding of online social capital has a positive and significant effect on the students' academic performance) were not approved. This finding means that usage of online tools for social capital does not necessarily increase students' academic performance. Some scholars, such as Naqshbandi et al. (2017) and Grenier (2018), believe that sometimes cyberspace and digital tools have negative effects on students' learning and academic performance. If the use of these interactive tools is not purposeful and in line with educational goals, it leads to cyberloafing and distraction and has negative effects on students' academic performance. Another finding of this study, namely the effect of online social capital on academic performance through knowledge sharing, confirms this explanation, which will be discussed later. This result is in line with the results presented by Neri and Ville (2008) but in contrast with the study of (Hasan \& Bagde, 2013; Mishra, 2020), who concluded that the academic performance of students will increase with the bonding of online social capital, e.g., through their relationship with their capable close friends, family, and roommates. Hypotheses 2-1 


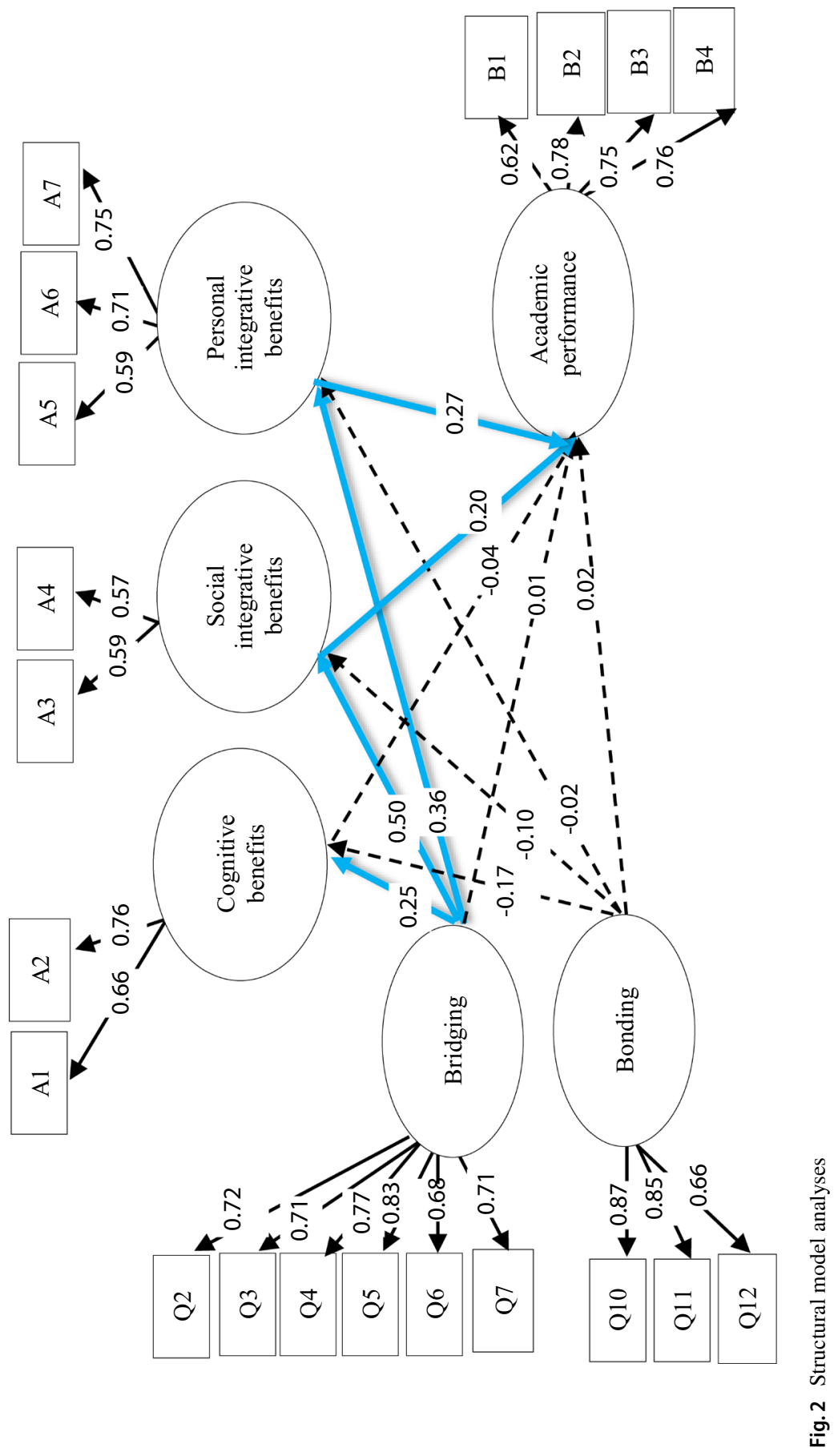


Table 5 Structural Equation Modeling: Hypotheses Testing

\begin{tabular}{|c|c|c|c|c|c|}
\hline Hypotheses & Relationships & & & Estimate & Conclusion \\
\hline H1-1 & Bridging & Academic performance & & 0.01 & Not Supported \\
\hline H1-2 & Bonding & Academic performance & & 0.02 & Not Supported \\
\hline H2-1 & $\mathrm{CB}$ & Academic performance & & -0.04 & Not Supported \\
\hline H2-2 & SIB & Academic performance & & $0.20^{*}$ & Supported \\
\hline H2-3 & PIB & Academic performance & & $0.27 * *$ & Supported \\
\hline H3-1 & Bridging & $\mathrm{CB}$ & & $0.25^{* *}$ & Supported \\
\hline H3-2 & Bridging & SIB & & $0.50 * * *$ & Supported \\
\hline H3-3 & Bridging & PIB & & $0.36 * * *$ & Supported \\
\hline H3-4 & Bonding & $\mathrm{CB}$ & & -0.17 & Not Supported \\
\hline H3-5 & Bonding & SIB & & -0.10 & Not Supported \\
\hline H3-6 & Bonding & PIB & & -0.02 & Not Supported \\
\hline \multirow[t]{2}{*}{ H4 } & Bridging & SIB & $\begin{array}{l}\text { Academic } \\
\text { performance }\end{array}$ & 0.1 & Supported \\
\hline & Bridging & PIB & $\begin{array}{l}\text { Academic } \\
\text { performance }\end{array}$ & 0.09 & Supported \\
\hline
\end{tabular}

Notes: $* \mathrm{p}<0.05 ; * * \mathrm{p}<0.01 ; * * * \mathrm{p}<0.001$

(CB has a positive and significant effect on students' academic performance), 2-2 (SIB has a positive and significant effect on students' academic performance), and 2-3 (PIB has a positive and significant effect on students' academic performance) investigated the relationship between the dimensions of knowledge sharing and students' academic performance. Consistent with the previous studies (Eid \& Al-Jabri, 2016; Aslam et al., 2014; Shah \& Mahmood, 2016), the result showed that only two of the advantages of online knowledge sharing (i.e., SIB and PIB) can affect the students' academic performance. The SIB and PIB dimensions refer to the personal and virtual group networks, students' academic reputations, and their connections with the group to influence each other's knowledge. This implies that the more students exchange information, the more they can enjoy the personal and social benefits of knowledge sharing, which can subsequently improve their academic performance. In other words, students' academic performance can improve as they increase their personal and virtual group networks (Olowo et al., 2020; Sivakumar, 2020); that is,

Table 6 Direct and indirect effect of variables

\begin{tabular}{llllll}
\hline Relationships & & & Direct Effect & Indirect Effect & Conclusion \\
\hline Bridging & CB & Academic performance & 0.01 & -0.01 & - \\
Bridging & SIB & Academic performance & -0.38 & 0.10 & Supported \\
Bridging & PIB & Academic performance & -0.38 & 0.09 & Supported \\
Bonding & CB & Academic performance & 0.02 & -0.006 & - \\
Bonding & SIB & Academic performance & 0.02 & -0.02 & - \\
Bonding & PIB & Academic performance & 0.02 & 0.005 & - \\
\hline
\end{tabular}


by joining different personal and virtual groups, not only can students benefit from the knowledge of others, but they can also influence others' knowledge to improve their academic performance. Moreover, sharing knowledge in different groups can improve students' academic reputations, which, as Green et al. (2008) suggest, can correspondingly enhance their academic performance.

Hypotheses 3-1 (bridging has a positive and significant effect on the CB), 3-2 (bridging has a positive and significant effect on the SIB), 3-3 (bridging has a positive and significant effect on the PIB), 3-4 (bonding has a positive and significant effect on the CB), 3-5 (bonding has a positive and significant effect on the SIB) and 3-6 (bonding has a positive and significant effect on the PIB) refer to the relationship between online social capital with the students' online knowledge sharing benefits. Our results, in line with those of the previous studies (e.g., Yan et al., 2019; AlAnsari et al., 2019; Lefebvre et al., 2016; García-Sánchez et al., 2019; Zhang et al., 2017), confirmed that bridging of online social capital has a positive and significant relationship with all dimensions of knowledge sharing benefits (CB, SIB, and PIB). This indicates that increased interactions and communication with others in online and virtual platforms will lead to the generation of more academic information and the improvement of such information (García-Sánchez et al., 2017). When students can freely and intimately interact with other students about their problems in cyberspace, they are more likely to feel that they are part of the online academic family. Social capital also facilitates the exchange and sharing of information by reducing the cost of accessing information through social interaction between social networks and increasing the willingness and cooperation to share information (Mou \& Lin, 2017). Nevertheless, despite the significant relationship between the bridging of online social capital and all dimensions of knowledge sharing benefits (CB, SIB, and PIB), no significant relationship was found between the bonding of online social capital and the benefits of knowledge sharing. The finding suggests that bridging of online social capital could be the foundation for successful knowledge sharing in online environments because high levels of social capital represent the existence of strong social networks, trusted relations, and social-behavioral norms, which can promote the creation and sharing of knowledge among members of the same community.

Hypothesis 4 concerned the mediating role of online knowledge sharing benefits (CB, SIB \& PIB) in the relationship between online social capital (bridging and bonding) and academic performance. In this regard, it was found that only the link between bridging of social capital, SIB, and academic performance, as well as the link between bridging of online social capital, PIB, and academic performance, were significant. This indicates that online social capital does not directly influence students' academic performance. The result is in line with Diep et al.'s (2017) findings which suggested that although online interactions have a significant effect on social capital growth, social capital does not have a significant effect on academic performance. In the current study, the results similarly indicated that online social capital had no direct effect on students' academic performance. Nevertheless, with the mediating role of online knowledge sharing benefits, online social capital had an indirect impact on students' academic performance. 


\section{Conclusion}

The results of this study demonstrated that online social capital could promote the academic performance of engineering students through two of the main advantages of online knowledge sharing, namely SIB and PIB. In other words, online social capital, without the intermediary benefits of knowledge sharing, did not affect students' academic performance. However, with the mediation of the benefits of knowledge sharing, the relationship between online social capital and students' academic performance became meaningful. Hence, it is only through the use of online knowledge sharing that students' online social capital can influence their academic performance. Accordingly, to improve the academic performance of our students, heed should be given to their online knowledge sharing. Hereby, we will not only promote their academic performance but also help them to expand their virtual communications and establish scientific networks. Therefore, academic administrators should consider students' knowledge sharing, encourage students to enhance their connections with other participants in the group, and expand their knowledge with their classmates to increase their academic performance. Accordingly, it is recommended that educators introduce online scientific groups in their courses and encourage students to communicate and share their information within the groups in their fields. Instructors could further provide discussion platforms in the form of social networks so as to promote the students' online knowledge sharing. Finally, it is advisable that students be introduced to specialized scientific networks and be encouraged to join these networks.

\subsection{Limitations}

The restrictions outlined below should be taken into consideration. First, the focus of this study was on engineering students. Therefore, the findings will be limited to the perceptions of this category of students, their context, their knowledge sharing infrastructures, and the professional skills they have developed. Second, the sample included 376 graduate students from two public universities and three major higher education institutions in Iran; therefore, it cannot be claimed that this sample represents all Iranian engineering students.

\subsection{Suggestions for future research}

The purpose of this study was to seek a better understanding of the relationship between online social capital, benefits of online knowledge sharing, and their impact on the academic performance of engineering students at five major universities and higher education institutions. The results of this study highlighted the importance of online knowledge sharing in engineering higher education environments from both individual and academic investment perspectives. Therefore, further research could investigate the various strategies that can be taught to students so they can gain greater advantages from their online knowledge sharing. It will be further insightful to apply the theoretical framework of this study in other educational environments to 
compare the results. In this regard, future research can also integrate local case studies with international studies to investigate the impact of individual and contextual factors such as culture, and type of education on students' academic performance. Finally, conducting qualitative research can potentially provide a more comprehensive understanding of how online social capital is developed and promotes the benefits of online knowledge sharing of engineering students.

Abbreviations CB: Cognitive benefits.; SIB: Social integrative benefits.; PIB: Personal integrating benefits.; IFI: Incremental fit index.; CFI: Comparative fit index.; RMSEA: Root-mean-square error of approximation.; AVA: Average variance extracted.; CR: Composite reliability

Acknowledgments We would like to thank all the engineering graduate students at two public universities and three higher education institutions who helped us improve data collection.

Availability of data and materials The datasets are available from the corresponding author on reasonable request.

Authors' contributions All the authors had the same role in Conceptualization, Methodology, Software, Data curation, writing- Original draft preparation, etc.

Funding None.

Conflict of interest The authors declare that they have no competing interests.

\section{References}

Ahmed, M. I., Mustaffa, C. S., \& Rani, N. S. A. (2020). Responding to Covid-19 via online learning: The relationship between Facebook intensity, community factors with social capital and academic performance. PalArch's Journal of Archaeology of Egypt/Egyptology, 17(6), 779-806.

Al-Ansari, M.A., Hamdan, A., Razzaque, A., Reyad, S., Al-Sartawi, A. (2019). The moderating role of m-learning activities in the relationship between students' social capital and knowledge sharing. International conference on e-learning 2019. Porto; Portugal, 139-146.

Almanthari, A., Maulina, S., \& Bruce, S. (2020). Secondary school mathematics teachers' views on E-learning implementation barriers during the COVID-19 pandemic: The case of Indonesia. Eurasia journal of mathematics, science and technology education, 16(7), em1860.

Almeida. M. V, Soares. A. L. (2014). Knowledge sharing in project-based organizations: Overcoming informational limbo. International Journal of Information Management, 34: 770-779.

Aslam, M. H., Siddiqi, A. F., Shahzad, K., \& Bajwa, S. U. (2014). Predicting student academic performance: Role of knowledge sharing and outcome expectations. International Journal of Knowledge Management (IJKM), 10(3), 18-35.

Asterhan, C., \& Bouton, E. (2017). Secondary school peer-to-peer knowledge sharing through social network technologies. : International Society of the Learning Sciences.

Bartscher, A. K., Seitz, S., Slotwinski, M., Siegloch, S., \& Wehrhöfer, N. (2020). Social capital and the spread of Covid-19: Insights from European countries.

Behtoui, A., \& Neergaard, A. (2016). Social capital and the educational achievement of young people in Sweden. British Journal of Sociology of Education, 37(7), 947-969.

Bevins, F., Bryant, J., Krishnan, C. \& Law, J. (2020). Coronavirus: How should US higher education plan for an uncertain future? (M. Sheikhan, trans. In collection of international reports on higher education and coronavirus crisis, Tehran, Iran: Institute for Social and Cultural Studies.

Borgonovi, F., \& Andrieu, E. (2020). Bowling together by bowling alone: Social capital and Covid-19. Social Science \& Medicine, 265, 113501. 
Bouton, E., Tal, S. B., \& Asterhan, C. S. (2021). Students, social network technology and learning in higher education: Visions of collaborative knowledge construction vs. the reality of knowledge sharing. The internet and higher education, 49, 100787.

Brown, T. A. (2015). Confirmatory factor analysis for applied research. Guilford publications.

Chen, Y. H., Lin, T. P., Yen, D. C. (2014). How to facilitate inter-organizational knowledge sharing: The impact of trust. Information \& Management, 51, 568-578.

Chiu, C. M., Hsu, M. H., \& Wang, E. T. (2006). Understanding knowledge sharing in virtual communities: An integration of social capital and social cognitive theories. Decision Support Systems, 42(3), 1872-1888.

Crompton, H., \& Burke, D. (2018). The use of mobile learning in higher education: A systematic review. Computers \& Education, 123, 53-64.

Daly, A. J., Liou, Y. H., \& Der-Martirosian, C. (2020). A capital idea: Exploring the relationship between human and social capital and student achievement in schools. Journal of Professional Capital and Community.

Diep, N. A., Cocquyt, C., Zhu, C., Vanwing, T., \& de Greef, M. (2017). Effects of core self-evaluation and online interaction quality on adults' learning performance and bonding and bridging social capital. The Internet and Higher Education, 34, 41-55.

Edmunds, J. A., Gicheva, D., Thrift, B., \& Hull, M. (2021). High tech, high touch: The impact of an online course intervention on academic performance and persistence in higher education. The Internet and Higher Education, 49, 100790.

Eid, M. I., \& Al-Jabri, I. M. (2016). Social networking, knowledge sharing, and student learning: The case of university students. Computers \& Education, 99, 14-27.

Ellison, N. B., Steinfield, C., \& Lampe, C. (2007). The benefits of Facebook "friends:” social capital and college students' use of online social network sites. Journal of Computer-Mediated Communication, 12(4), 1143-1168.

Fong, K. C. H., Au, C. H., Lam, E. T. H., \& Chiu, D. K. (2020). Social network services for academic libraries: A study based on social capital and social proof. The Journal of Academic Librarianship, 46(1), 102091.

Ford, D. P., \& Staples, S. (2010). Are full and partial knowledge sharing the same? Journal of Knowledge Management, 14(3), 394-409.

Fornell, C., \& Larcker, D. F. (1981). Evaluating structural equation models with unobservable variables and measurement error. Journal of Marketing Research, 18(1), 39-50 https://doi.org/10.1177/00222 4378101800104

García-Sánchez, P., Díaz-Díaz, N. L., \& De Saá-Pérez, P. (2019). Social capital and knowledge sharing in academic research teams. International Review of Administrative Sciences, 85(1), 191-207.

Grenier, D. P. (2018). The relationship between mobile learning and academic achievement in a community college system online environment. Liberty University.

Hall, H., \& Widén-Wulff, G. (2008). Social exchange, social capital and information sharing in online environments: Lessons from three case studies. From information provision to knowledge production: Proceedings of the international conference for the celebration of the 20th anniversary of information studies, Faculty of Humanities, University of Oulu, Finland, 8, 73-86.

Hair Jr, J. F., Hult, G. T. M., Ringle, C., \& Sarstedt, M. (2016). A primer on partial least squares structural equation modeling (PLS-SEM). Sage publications.

Hasan, S., \& Bagde, S. (2013). The mechanics of social capital and academic performance in an Indian college. American Sociological Review, 78(6), 1009-1032.

Heidari, E., Salimi, G., \& Mehrvarz, M. (2020). The influence of online social networks and online social capital on constructing a new graduate students' professional identity. Interactive Learning Environments, 1-18.

Heidari, E., Mehrvarz, M., Marzooghi, R., \& Stoyanov, S. (2021). The role of digital informal learning in the relationship between students' digital competence and academic engagement during the COVID-19 pandemic. Journal of Computer Assisted Learning.

Hubbard, P. (2019). Leveraging technology to integrate informal language learning within classroom settings. In M. Dressman \& R. W. Sadler (Eds.), The handbook of informal language learning (pp. 405-419). John Wiley \& Sons Ltd.

Hung, H. P. (2005). Ethnicity, gender, and the academic performance of adolescents: An examination of the influence of culture. 
Iglesias-Pradas, S., Hernández-García, Á., Chaparro-Peláez, J., \& Prieto, J. L. (2021). Emergency remote teaching and students' academic performance in higher education during the COVID-19 pandemic: A case study. Computers in Human Behavior, 119, 106713.

Iqbal, J., Qureshi, N., Ashraf, M. A., Rasool, S. F., \& Asghar, M. Z. (2021). The effect of emotional intelligence and academic social networking sites on academic performance during the COVID-19 pandemic. Psychology Research and Behavior Management, 14, 905.

Islam, M. M., Habes, E. M., \& Alam, M. M. (2018). The usage and social capital of mobile phones and their effect on the performance of microenterprise: An empirical study. Technological Forecasting and Social Change, 132, 156-164.

Lefebvre, V. M., Sorenson, D., Henchion, M., \& Gellynck, X. (2016). Social capital and knowledge sharing performance of learning networks. International Journal of Information Management, 36(4), 570-579.

Li, S. M. (2015). Exploring the perceived accounting ethics of university students on online knowledge sharing. In new media, knowledge practices and multiliteracies (pp. 133-148). Springer, .

Liao, T. H. (2017). Developing an antecedent model of knowledge sharing intention in virtual communities. Universal Access in the Information Society, 16(1), 215-224.

Lin, N. (2017). Building a network theory of social capital. In social capital (pp. 3-28). Routledge.

Ma, W. W., \& Yuen, A. H. (2011). Understanding online knowledge sharing: An interpersonal relationship perspective. Computers \& Education, 56(1), 210-219.

Mehrvarz, M., Heidari, E., Farrokhnia, M., \& Noroozi, O. (2021). The mediating role of digital informal learning in the relationship between students' digital competency and their academic performance. Computers \& Education, 104184.

Mishra, S. (2020). Social networks, social capital, social support and academic success in higher education: A systematic review with a special focus on 'underrepresented'students. Educational Research Review, 29, 100307.

Moghavvemi, S., Sharabati, M., Klobas, J. E., \& Sulaiman, A. (2018). Effect of trust and perceived reciprocal benefit on students' knowledge sharing via facebook and academic performance.

Mou, Y., \& Lin, C. A. (2017). The impact of online social capital on social trust and risk perception. Asian Journal of Communication, 27(6), 563-581.

Mthimunye, K. D. T., \& Daniels, F. M. (2020). Exploring the challenges and efforts implemented to improve the academic performance and success of nursing students at a university in the Western cape. International journal of Africa nursing sciences, 100196.

Naqshbandi, M. M., Ainin, S., Jaafar, N. I., \& Shuib, N. L. M. (2017). To Facebook or to face book? An investigation of how academic performance of different personalities is affected through the intervention of Facebook usage. Computers in Human Behavior, 75, 167-176.

Neri, F., \& Ville, S. (2008). Social capital renewal and the academic performance of international students in Australia. The Journal of Socio-Economics, 37(4), 1515-1538.

Nkhoma, M., Cong, H. P., Au, B., Lam, T., Richardson, J., Smith, R., \& El-Den, J. (2015). Facebook as a tool for learning purposes: Analysis of the determinants leading to improved students' learning. Active Learning in Higher Education, 16(2), 87-101.

Nouri, J., Zhang, L., Mannila, L., \& Norén, E. (2020). Development of computational thinking, digital competence and 21st century skills when learning programming in K-9. Education Inquiry, 11(1), $1-17$.

Olowo, B. F., Alabi, F. O., Okotoni, C. A., \& Yusuf, M. A. (2020). Social media: Online modern tool to enhance secondary schools' students' academic performance. International Journal on Studies in Education, 2(1), 26-35.

Oranye, N. O., Ezeah, P., \& Ahmad, N. (2017). Elements of social capital and academic performance of undergraduate students. Social Indicators Research, 131(1), 305-319.

Paige, S. R., Stellefson, M., Chaney, B. H., Chaney, D. J., Alber, J. M., Chappell, C., \& Barry, A. E. (2017). Examining the relationship between online social capital and eHealth literacy: Implications for Instagram use for chronic disease prevention among college students. American Journal of Health Education, 48(4), 264-277.

Perez, C., Sokolova, K., \& Konate, M. (2020). Digital social capital and performance of initial coin offerings. Technological Forecasting and Social Change, 152, 119888.

Pitas, N., \& Ehmer, C. (2020). Social Capital in the Response to COVID-19. American Journal of Health Promotion, 34(8), 942-944.

Rasto, R., Muhidin, S. A., Islamy, F. J., \& Handayani, D. (2021). The influence of knowledge sharing and competence on academic performance. Cypriot Journal of Educational Sciences, 16(3), 928-938. 
Sabatini, F., \& Sarracino, F. (2014). Will Facebook save or destroy social capital. An empirical investigation into the effect of online interactions on trust and networks. EERI research paper series EERI $R P$ 2014/02, economics and econometrics research institute (EERI), Brussels.

Sivakumar, R. (2020). Effects of social media on academic performance of the students. The Online Journal of Distance Education and e-Learning, 8(2), 90.

Shah, S. R., \& Mahmood, K. (2016). Contributing factors in knowledge sharing for the performance of university students in teachers' training programs. Library Management, 37(8/9), 496-506.

Sharabati, M. M. (2018). The impact of knowledge sharing through social networks on students' academic performance. International Journal of Business and Information.

Suparsa, I. M., Setini, M., Asih, D., \& Telagawathi, N. L. W. S. (2021). Teacher performance evaluation through knowledge sharing and technology during the COVID 19 pandemic. Management.

Tonteri, L., Kosonen, M., Ellonen, H. K., \& Tarkiainen, A. (2011). Antecedents of an experienced sense of virtual community. Computers in Human Behavior, 27(6), 2215-2223.

Toquero, C. M. (2020). Challenges and opportunities for higher education amid the COVID-19 pandemic: The Philippine context. Pedagogical Research, 5(4).

Wu, C. (2021). Social capital and COVID-19: A multidimensional and multilevel approach. Chinese Sociological Review, 53(1), 27-54.

Yan, J., Leidner, D. E., Benbya, H., \& Zou, W. (2019). Social capital and knowledge contribution in online user communities: One-way or two-way relationship? Decision Support Systems, 127, 113131.

Yu, A. Y., Tian, S. W., Vogel, D., \& Kwok, R. C. W. (2010b). Can learning be virtually boosted? An investigation of online social networking impacts. Computers \& Education, 55(4), 1494-1503.

Yu, T. K., Lu, L. C., \& Liu, T. F. (2010a). Exploring factors that influence knowledge sharing behavior via weblogs. Computers in Human Behavior, 26(1), 32-41.

Zhang, X., Liu, S., Chen, X., \& Gong, Y. (2017). Social capital, motivations, and knowledge sharing intention in health Q\&a communities. Management Decision, 55(7), 1536-1557.

Zhou, J. (2017). Exploring the factors affecting learners' continuance intention of MOOCs for online collaborative learning: An extended ECM perspective. Australasian Journal of Educational Technology, 33(5).

Publisher's note Springer Nature remains neutral with regard to jurisdictional claims in published maps and institutional affiliations. 